\title{
Optimization of Lab-Scale Preparation of Biodiesel from Rubber Seed Oil Using Modified Calcium Oxide as Catalyst
}

\author{
Uma Krishnakumar, V. Sivasubramanian* \\ Department of Chemical Engineering, National Institute of Technology Calicut (NITC), Calicut, India \\ Email: ${ }^{*}$ siva@nitc.ac.in
}

Received 13 January 2016; accepted 5 July 2016; published 8 July 2016

Copyright (C) 2016 by authors and Scientific Research Publishing Inc.

This work is licensed under the Creative Commons Attribution International License (CC BY).

http://creativecommons.org/licenses/by/4.0/

(c) (i)

Open Access

\begin{abstract}
Statistical analysis of product yield for biodiesel preparation by transesterification process was performed using the Minitab software. A standard RSM Design tool known as CCD was applied to study the transesterification reaction variables. The obtained parameters were verified experimentally for the transesterification reaction of rubber seed oil using solid metal oxide catalyst. The factors affecting the methyl ester yield during transesterification reaction were identified as the catalyst content, molar ratio of oil to alcohol and reaction time. High methyl ester yield and fast reaction rate could be obtained even if reaction temperature was relatively low, which is quite favorable to the industrial production of biodiesel from the rubber seed oil. $98.54 \%$ of methyl ester was formed from the transesterification of RSO with methanol. R-squared is a statistical measure of how close the data are to the fitted regression line. It is also known as the coefficient of determination, or the coefficient of multiple determination for multiple regression. In this study, an $R^{2}$ value of 0.98 is obtained.
\end{abstract}

\section{Keywords}

Biodiesel, Rubber Seed Oil, Transesterification, Calcium Oxide

\section{Introduction}

Biodiesel is defined as a fuel comprised of mono-alkyl esters of long chain fatty acids derived from vegetable oils or animal fats. It is non-toxic, biodegradable and available, has a high heat value, high oxygen content (10 to $11 \%)$ and does not contain sulfurs and aromatic compounds. Biodiesel is a plant derived product and it contains

${ }^{*}$ Corresponding author.

How to cite this paper: Krishnakumar, U. and Sivasubramanian, V. (2016) Optimization of Lab-Scale Preparation of Biodiesel from Rubber Seed Oil Using Modified Calcium Oxide as Catalyst. Journal of Sustainable Bioenergy Systems, 6, 55-65. http://dx.doi.org/10.4236/jsbs.2016.63006 
oxygen in its molecule, making it a cleaner burning fuel than petrol and diesel. Several studies have showed that biodiesel is a better fuel than fossil based diesel in terms of engine performance, emissions reduction, lubricity, and environmental benefits. The current feed stocks for production of biodiesel or mono-alkyl ester are vegetable oil, animal fats and micro algal oil. Despite the considerable potential of biodiesel, the production of biodiesel is found to be expensive from edible oils owing to the growing demand for edible oils and the high cost of the feedstock. According to previous reports, the raw materials for biodiesel production account for almost $75 \%$ of the total biodiesel cost. Hence future of the biodiesel is going to be limited unless biodiesel can be extracted from other non edible raw materials. Use of cost effective non edible oils are getting more prominence in this context. The present investigation aims to evaluate the performance of the solid metal oxide catalyst, $\mathrm{CaO}$ for the transesterification reaction of rubber seed oil. Experimental studies will be conducted to investigate the effects of main parameters, including methanol to rubber seed oil ratio, catalyst to oil weight ratio, reaction temperature and reaction time to obtain the optimal condition [1]-[4].

\section{Materials \& Methods}

Crude rubber seed oil had been selected as a potential feedstock for biodiesel preparation. Oil used is non-edible and is commercially obtained after extraction from rubber seeds. Methanol with a purity of $99.5 \%$ and $\mathrm{CaO}$ (for modification) is commercially obtained.

\subsection{Biodiesel Preparation}

A bench scale set-up consisted mainly of a round glass reactor placed in an adjusted temperature bath is used for the transesterification reaction is shown in Figure 1(a). This flask was provided with condenser; magnetic stirrer and thermometer for temperature follow up and funnel for methanol addition. A calculated amount of Calcium oxide was dipped in sufficient quantity of ammonium carbonate solution then the mixture was stirred for 30 minutes at room temperature. After filtration and drying at $112^{\circ} \mathrm{C}$ till constant weight, the dried solid was milled and sieved then calcined at $850^{\circ} \mathrm{C}$ for $1.5 \mathrm{hrs}$. After cooling in a dessicator to room temperature the base $\mathrm{CaO}$ is ready to use. High temperature calcinations of $\mathrm{CaO}$ improved the performance of the catalyst [5]-[8].

Measured amount of methanol $+\mathrm{CaO}$ stirred by a magnetic stirrer for 10 minutes after which it was preheated to about $65^{\circ} \mathrm{C}$ below the boiling point of methanol. Thereafter, oil was taken and heated to $65^{\circ} \mathrm{C}$ on a temperature water bath before it was poured into a blender. Methanol and prepared $\mathrm{CaO}$ were then poured gently into the RSO in the blender. The entire content was allowed to blend for the required reaction time. After the completion of reaction, the reaction product was decanted from the blender \& centrifuged at $6000 \mathrm{rpm}$ for $10 \mathrm{mi}-$ nutes, where the $\mathrm{CaO}$ catalyst was separated from the reaction product. Then the supernatant product mixture was exposed to open air for 30 minutes to evaporate excess methanol. Thereafter, it was poured into a separating funnel and allowed to settle overnight so as to separate the glycerine from the biodiesel Figure 1(b). The lower glycerine layer was drawn off and the upper biodiesel layer was then removed, dried and weighed [9]-[11].

\subsection{Theoretical Optimization}

Statistical analysis of product yield was performed using the Minitab software. A standard RSM Design tool

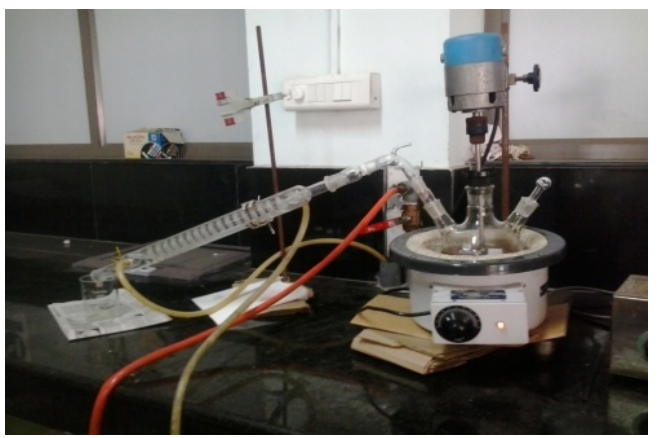

(a)

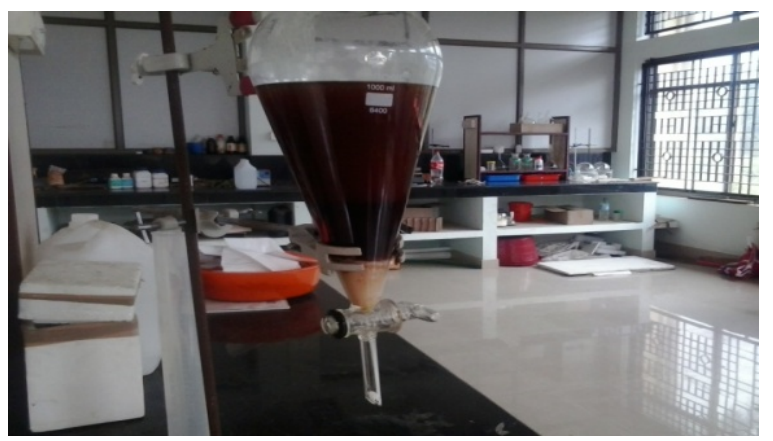

(b)

Figure 1. (a) Bench scale set up for biodiesel preparation; (b) product obtained after transesterification. 
known as CCD was applied to study the transesterification reaction variables. The four factors investigated were A: Oil to Alcohol molar ratio, B: Catalyst to oil weight ratio, C: Reaction time and D: Reaction temperature. The response chosen was biodiesel yield which was obtained from the reaction. The quality of fit for the model was evaluated by the coefficient of determination $\left(\mathrm{R}^{2}\right)$ and its regression coefficient. Significance of ANOVA was also checked. 3-D surface and 2-D contour plots were developed using the quadratic polynomial equation obtained from regression analysis of experimental data by keeping two of the independent variables at a constant value while changing the other two variables [12]-[15].

In statistical significance testing, the p-value is the probability of obtaining a test statistic result at least as extreme as the one that was actually observed, assuming that the null hypothesis is true. A researcher will often "reject the null hypothesis" when the p-value turns out to be less than a predetermined significance level, often 0.05 or 0.01 . Such a result indicates that the observed result would be highly unlikely under the null hypothesis [16] [17].

\subsection{Central Composite Design}

The effect of four variables on biodiesel yield was studied by the Response Surface Methodology. Experimental design was based on RSM analysis. For RSM analysis based on CCD, 30 experiments were performed in triplicate. The variables were coded according to the equation:

$$
X_{i}=\frac{\left[X_{i}-X_{o}\right]}{\Delta X}
$$

where $x_{i}$ is the coded value of the $i^{\text {th }}$ variable, $X_{i}$ is the encoded value of the $i^{\text {th }}$ test variable and $X_{o}$ is the encoded value of the $i^{\text {th }}$ test variable at center point. The regression analysis was performed to estimate the response function as a second order polynomial:

$$
Y=\beta_{o}+\sum_{i=1}^{n} \beta_{o} X_{i}+\sum_{i=1}^{n} \sum_{j=1}^{i-1} \beta_{i j} X_{i} X_{j}
$$

where $Y$ is the predicted response, $\beta_{i}$ and $\beta_{i j}$ are coefficients estimated from regression, they represent the linear, quadratic and cubical effect of $x_{1}, x_{2}, x_{3} \ldots \ldots$ on response [18]-[20].

\section{Results and Discussion}

\subsection{Alcohol to Oil Molar Ratio}

Many researchers recognized that one of the main factors affecting the yield of biodiesel is the molar ratio of alcohol to oil (triglyceride). Theoretically, the ratio for transesterification reaction requires $3 \mathrm{~mol}$ of alcohol for $1 \mathrm{~mol}$ of triglyceride to produce $3 \mathrm{~mol}$ of fatty acid ester and $1 \mathrm{~mol}$ of glycerol. An excess of alcohol is used in biodiesel production to ensure that the oils or fats will be completely converted to esters and a higher alcohol triglyceride ratio can result in a greater ester conversion in a shorter time. Yield of biodiesel is increased when alcohol triglyceride ratio is raised beyond 3 to an optimum value which marks the maximum yield. Furthermore increasing alcohol amount beyond the optimal ratio will not increase the yield, but will increase cost for alcohol recovery. In this study five experiments were conducted as shown in Table 1 varying the molar ratio of methanol

Table 1. Influence of methanol to oil molar ratio on biodiesel yield.

\begin{tabular}{cccccc}
\hline SI No & Methanol to oil molar ratio & Mass of oil (g) & Mass of methanol (g) & Weight of methyl ester collected (g) & Yield \% \\
\hline 1 & $3: 1$ & 130.86 & 14.4 & 111.36 & 85.01 \\
2 & $3.5: 1$ & 130.86 & 16.8 & 117.5 & 89.78 \\
3 & $4: 1$ & 130.86 & 19.2 & 129.11 & 98.66 \\
4 & $4.5: 1$ & 130.86 & 21.6 & 129.6 & 99.20 \\
5 & $5: 1$ & 130.86 & 24 & 87.24 & 66.67 \\
\hline
\end{tabular}


to oil, and a methyl ester conversion of $99.2 \%$ was obtained for a 4.5:1 methanol:oil molar ratio.

\subsection{Catalyst to Oil Weight Ratio}

Amount of $\mathrm{CaO}$ is vital in this transesterification process. More amount of catalyst will lead to the additional cost as well as the complexity of the catalyst removal. The influence of amount of calcium oxide as catalyst on biodiesel yield is shown in Table 2. As shown in Figure 2(a) the highest yield of 96.11\% was obtained for a catalyst amount of 0.76 gram (0.59 wt\%). As a consequence of these results, all other experiments were carried with a catalyst to oil ratio of $0.6: 1$.

\subsection{Optimization of Reaction Temperature}

Temperature is one of the factors that influence the reaction and yield of the biodiesel product. A higher reactiontemperature can decrease the viscosities of oils and results in an increased reaction rate, and a shortened reaction time. However, high reaction temperature can decrease biodiesel yield because a higher reaction temperature accelerates the saponification reaction of triglycerides. Reaction temperature must be lower than the boiling point of alcohol in order to ensure that the alcohol will not leak out through vaporization. The effect of temperature in the transesterification reaction of rubber seed oil is shown in Figure 2(b). The results show that the reaction temperature influences the formation of methyl ester (ME). The formation of ME increases with the increase of reaction temperature but drops drastically at $70^{\circ} \mathrm{C}$. The initial increase in the yield may be due to the vaporization of the fatty acid contents in the mixture which may encourage the forward reaction to form ME (14). At high temperatures the reaction may slows down may be due to the alcohol evaporation. As it can be seen in Figure 2(c), high biodiesel conversions were obtained at temperatures near to the boiling point of methanol $\left(64.7^{\circ} \mathrm{C}\right)$.

\subsection{Optimization of the Reaction Time}

The effect of reaction time on the transesterification reaction of RSO using CaO catalyst is shown in Figure 2(a). As reaction time increases from 1 to 5 hours, the percentage yield found to be increasing initially and found to be decreasing at higher reaction times. A reaction time of 1.5 hours gives a maximum yield of $96.45 \%$. In this, effects of the process parameters such as 1) Alcohol to oil molar ratio; 2) Catalyst to oil weight ratio; 3) reaction temperature and 4) reaction time on biodiesel yield in the transesterification reactions of rubber seed oil using the solid metal oxide catalyst $(\mathrm{CaO})$ has been analyzed. Based on this study a set of optimized conditions were identified which has been summarized in Table 3 .

\subsection{Theoretical Optimization}

Using software Minitab 17, factorial design with replications can be done by finding the critical process variables and developing a regression model. Full factorial DOE (Design of Experiments) is a planned set of tests on the response variables with one or more inputs (factors) with all combinations of levels. In this, first we have to define the design and factors in the process with their low/high values as shown in Table 4.

Perform the analysis of the factorial design of the process by setting the maximum order for terms in the

Table 2. Influence of amount of $\mathrm{CaO}$ (catalyst) on biodiesel yield.

\begin{tabular}{cccccc}
\hline SI No & Catalyst to oil weight ratio & Mass of oil (g) & Catalyst amount (g) & Weight of methyl ester collected (g) & Yield \% \\
\hline 1 & $0.2: 1$ & 130.86 & 0.26 & 107.59 & 82.22 \\
2 & $0.4: 1$ & 130.86 & 0.52 & 117.84 & 90.05 \\
3 & $0.6: 1$ & 130.86 & 0.78 & 125.77 & 96.11 \\
4 & $0.8: 1$ & 130.86 & 1.05 & 105.62 & 80.71 \\
5 & $1: 1$ & 130.86 & 1.31 & 97.15 & 74.24 \\
\hline
\end{tabular}



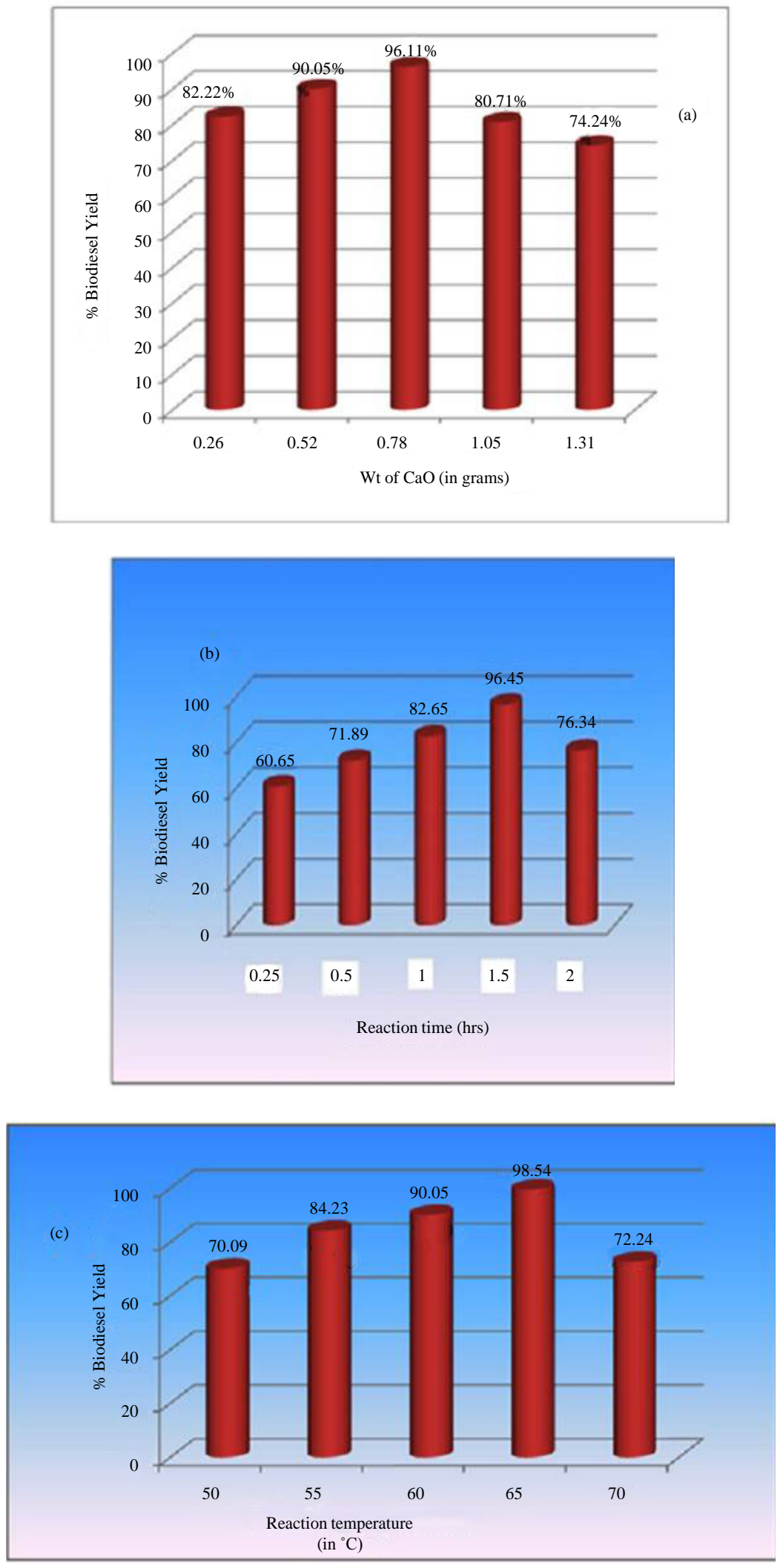

Figure 2. (a) Influence of amount of $\mathrm{CaO}$ (catalyst); (b) influence of reaction temperature and (c) influence of reaction time on biodiesel yield. 
model as "2" and the assumptions are validated. Then the normal probability plot, versus fits and normal plot of standardized effects are obtained as shown in Figure 3 \& Figure 4. The results show that both normality and constant variance assumptions were met. From the Figure 5, significant factors are obtained.

In Minitab 17, p-value is a measure of strength of evidence against null hypothesis. P-value can be defined as the probability of getting the observed value of test statistic, or a value with even greater evidence against the hypothesis, if it is actually true. Analysis of variance for transformed response is shown in Table 5.

Main effects plot, interaction plot, contour plots of yield \% and surface plots of yield \% are shown in Figures 6-9 respectively. Fits and diagnostics for unusual observations is shown in Table 6.

Table 3. Optimized conditions for Biodiesel production from RSO.

\begin{tabular}{ccc}
\hline SI No & Parameter & Condition \\
\hline 1 & Alcohol to oil molar ratio & $4.5: 1$ \\
2 & Catalyst to oil weight ratio & $0.6: 1$ \\
3 & Reaction time & $1.5 \mathrm{hrs}$ \\
4 & Reaction temperature & $65^{\circ} \mathrm{C}$ \\
\hline
\end{tabular}

Table 4. Symbols \& uncoded levels of parameters.

\begin{tabular}{cccc}
\hline Factors & Symbol & Low & 3 \\
Alcohol to oil molar ratio & A & 0.2 \\
Catalyst to oil weight ratio & B & 0.25 \\
Reaction time in hours & C & 2 \\
Temperature in degree C & D & 50 \\
\hline
\end{tabular}

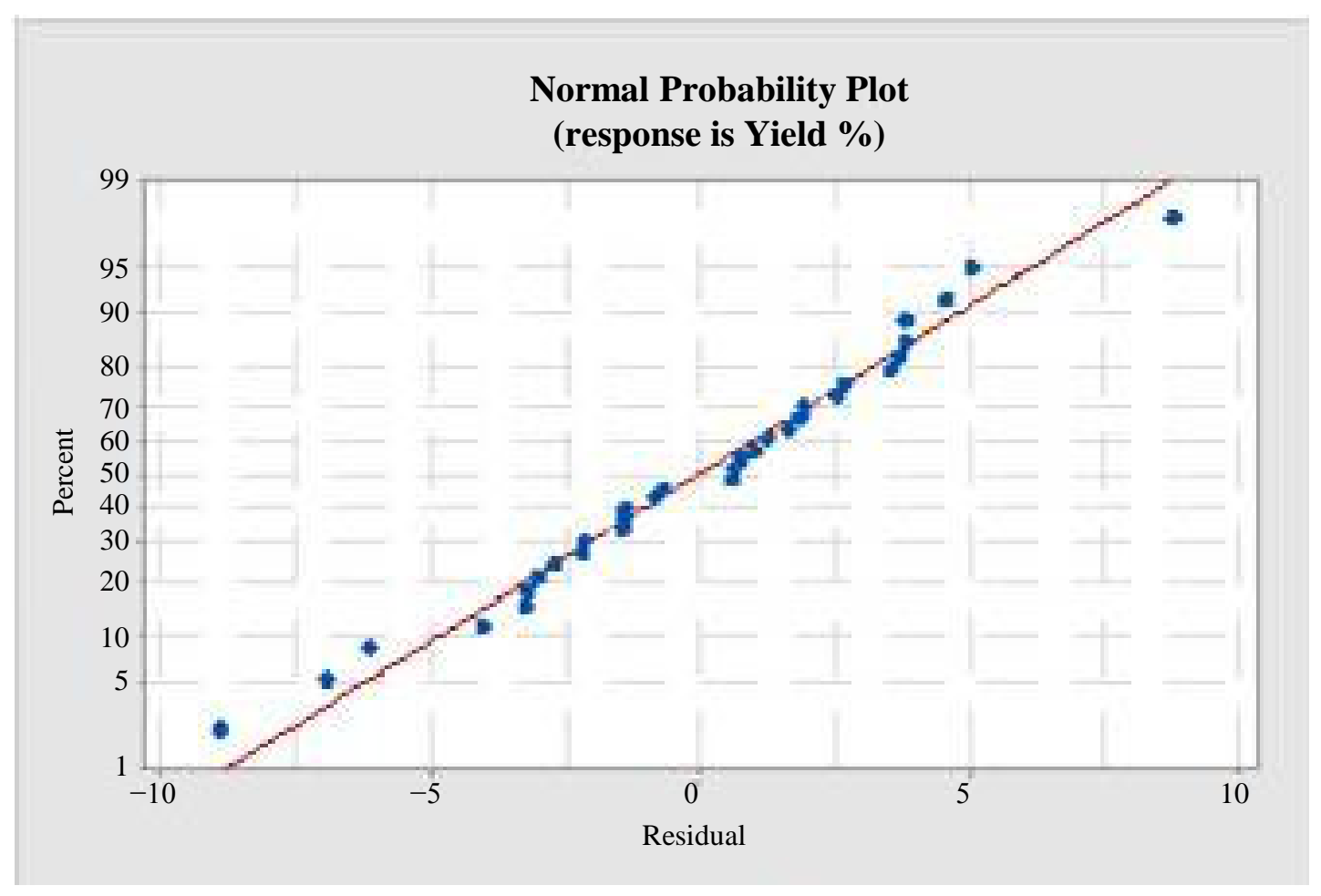

Figure 3. Normal probability plot. 


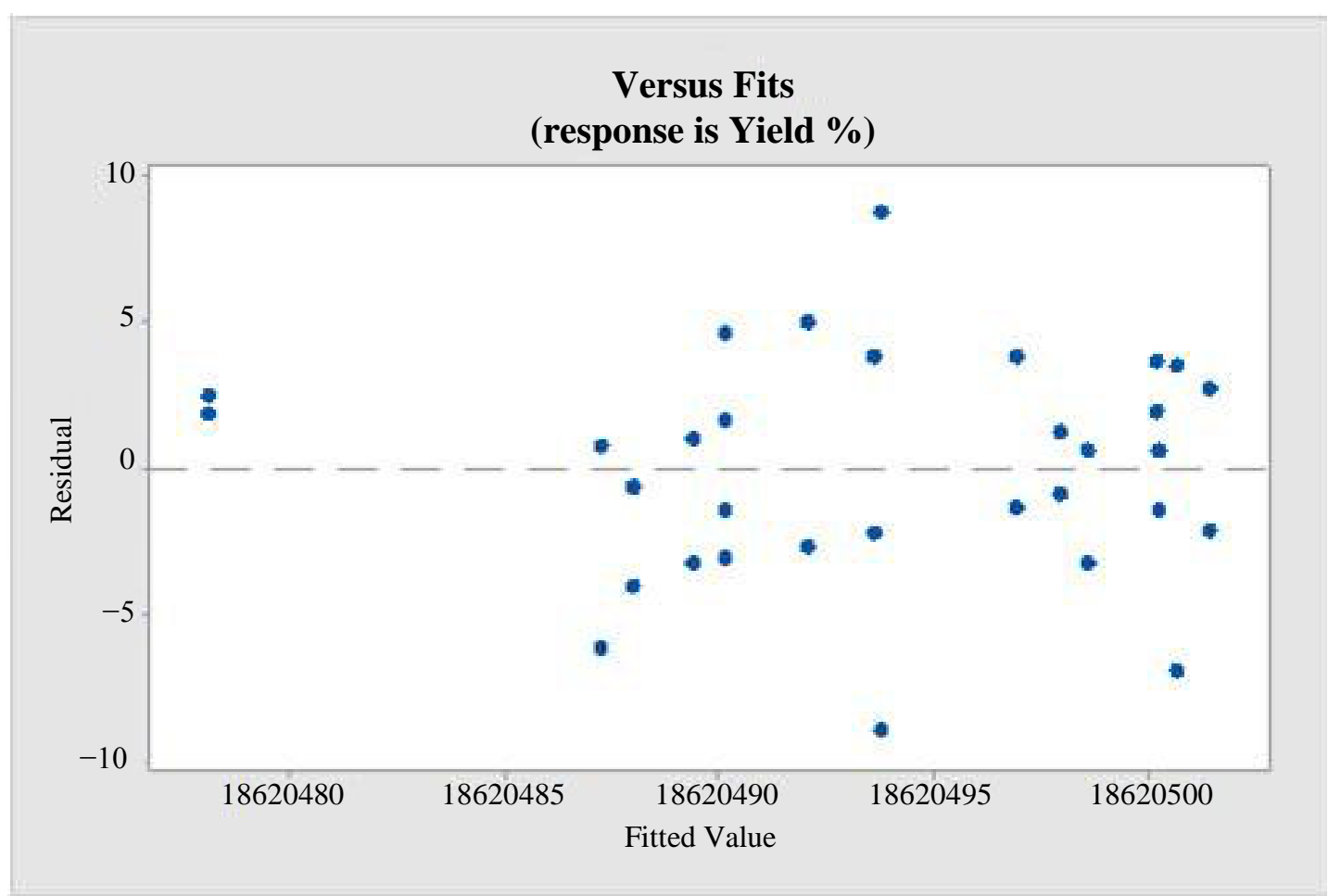

Figure 4. Residual versus fits.

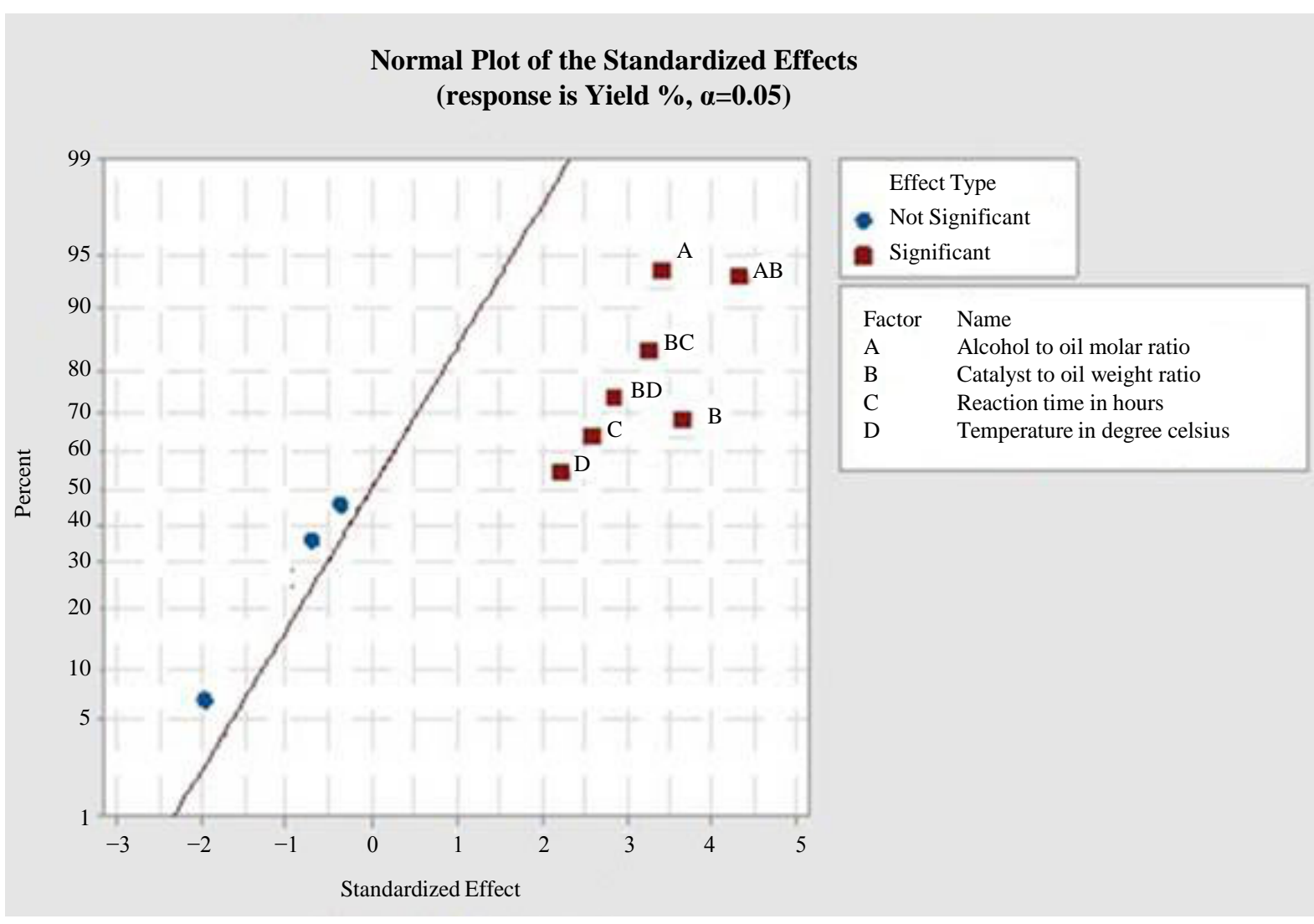

Figure 5. Normal plot of standardized effects. 
Table 5. Analysis of variance for transformed response.

\begin{tabular}{ll}
\hline Source & p-value \\
\hline Model & 0.000 \\
Linear & 0.016 \\
Alcohol to oil molar ratio & 0.361 \\
Catalyst to oil weight ratio & 0.094 \\
Reaction time in hours & 0.017 \\
Temperature in degree Celsius & 0.037 \\
2-way interactions & 0.000 \\
Alcohol to oil molar ratio*Catalyst to oil weight ratio & 0.482 \\
Alcohol to oil molar ratio*Reaction time in hours & 0.063 \\
Alcohol to oil molar ratio*Temperature in degree celsius & 0.004 \\
Catalyst to oil weight ratio*Reaction time in hours & 0.009 \\
Catalyst to oil weight ratio*Temperature in degree celsius & 0.722 \\
Reaction time in hours*Temperature in degree celsius & 0.654 \\
Lack of fit & \\
\hline
\end{tabular}

\section{Main Effects Plot for Yield \%}

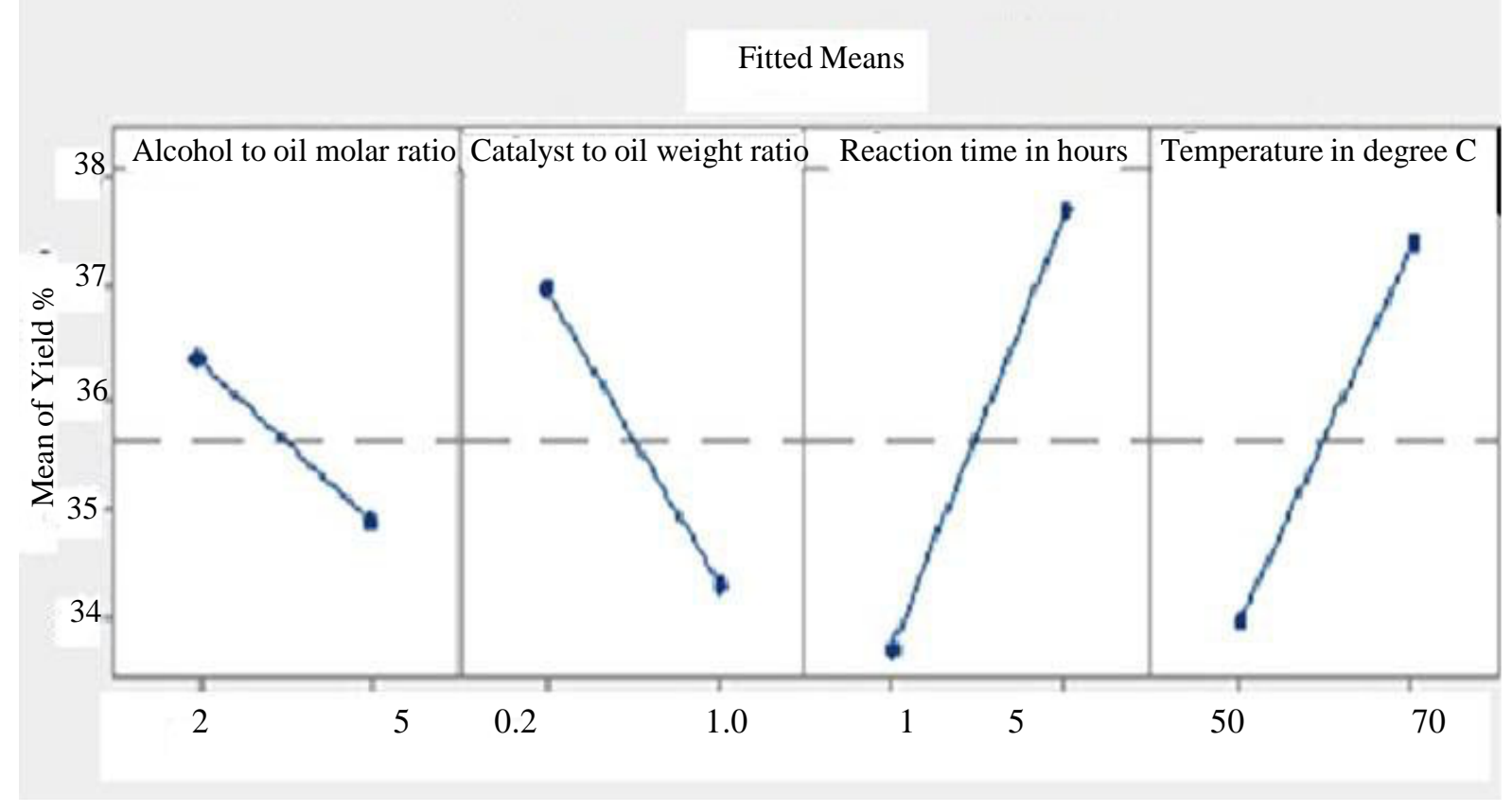

\section{Figure 6. Main effects plot.}

\section{Conclusion}

98.54\% of methyl ester was formed from the transesterification of RSO with methanol. The factors affecting the methyl ester yield during transesterification reaction were the catalyst content, molar ratio of oil to alcohol and reaction time. High methyl ester yield and fast reaction rate could be obtained even if reaction temperature was 


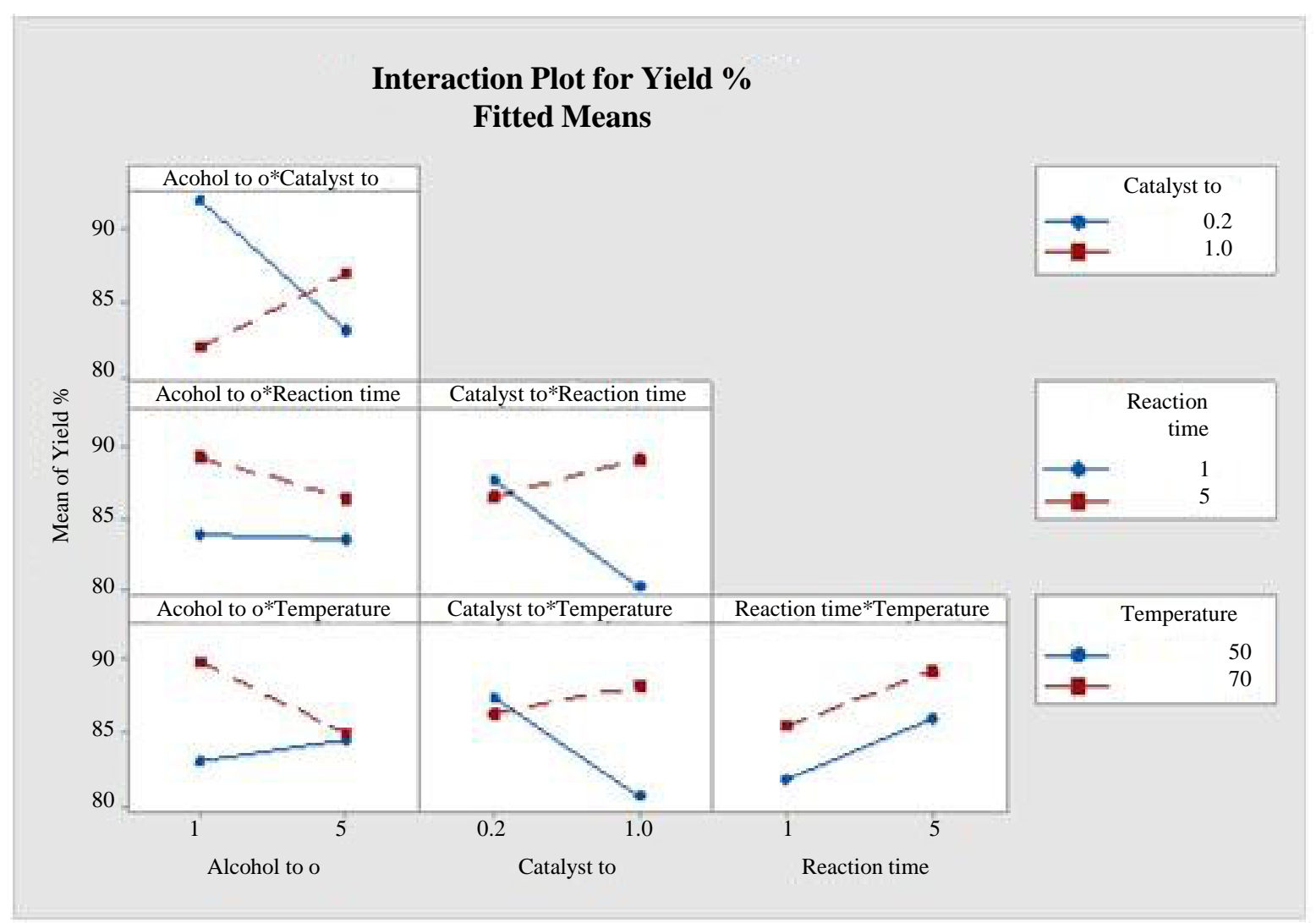

Figure 7. Interaction plot.

\section{Contour Plots of Yield \%}
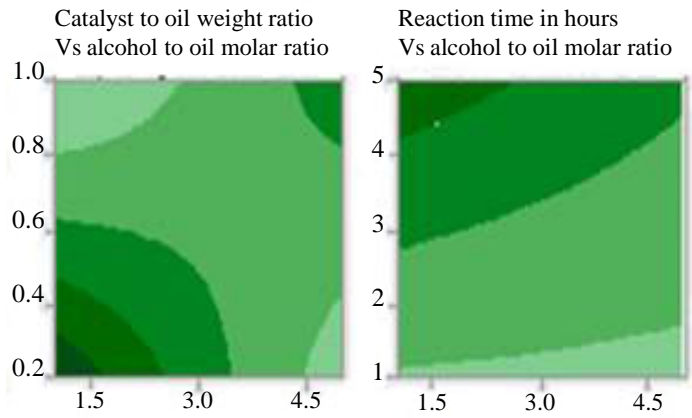

Temperature in degree $\mathrm{C}$

Vs alcohol to oil molar ratio

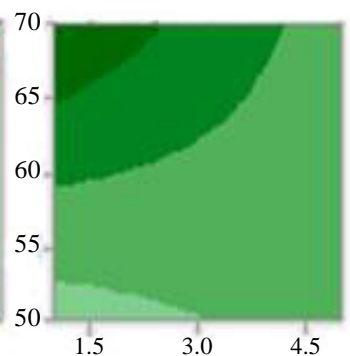

Reaction time in hours

Temperature in degree $\mathrm{C}$

Vs catalyst to oil weight ratio

Vs catalyst to oil weight ratio

Temperature in degree $\mathrm{C}$

Vs alcohol to oil molar ratio
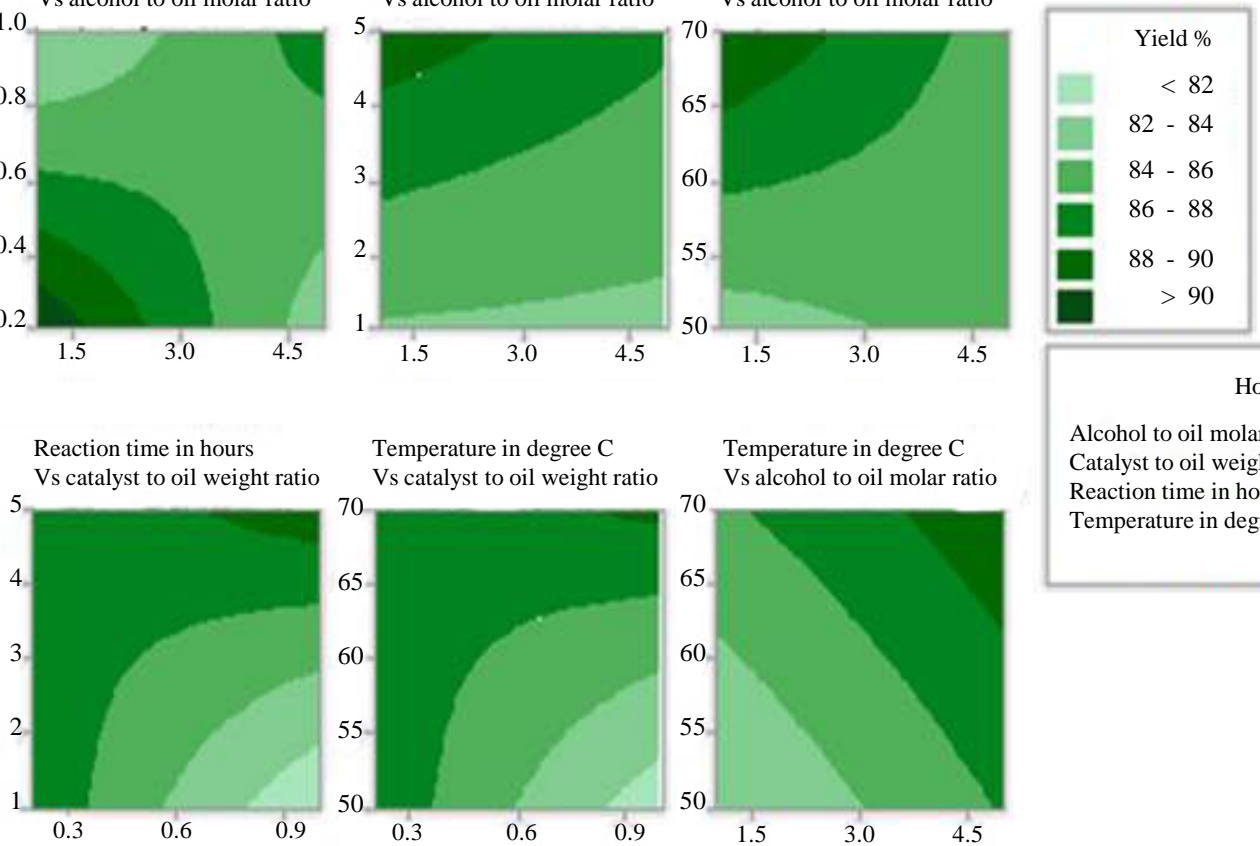

Hold Values

Alcohol to oil molar ratio

Catalyst to oil weight ratio

Reaction time in hours

Temperature in degree celsius

Figure 8. Contour plots of yield \%. 

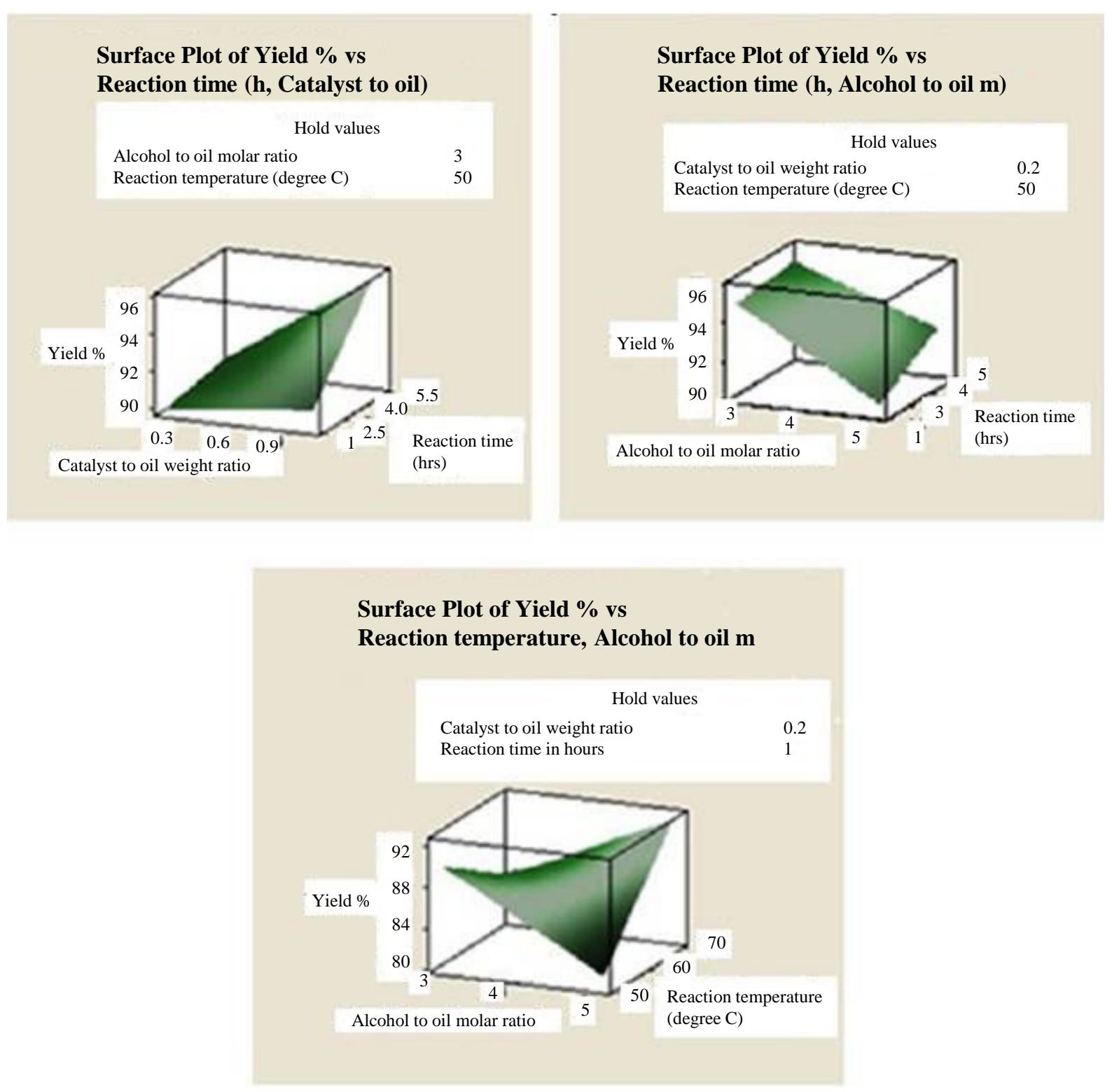

Figure 9. Surface plots of yield \%.

Table 6. Fits and diagnostics for unusual observation.

\begin{tabular}{ccccc}
\hline Obs & Yield $\%$ & Fit & Resid & Std Resid \\
\hline 2 & 96.40 & 83.40 & 12.99 & $2.06 \mathrm{R}$ \\
30 & 76.14 & 91.12 & -14.98 & $-2.37 \mathrm{R}$ \\
\hline
\end{tabular}

relatively low, which is quite favorable to the industrial production of biodiesel from the rubber seed oil. Results of optimization test showed complete formation of methyl ester under the following circumstances; reaction duration: 1.5 hours, temperature: $65^{\circ} \mathrm{C}$, catalyst to oil weight ratio of $0.6: 1$ and with an alcohol to oil molar ratio of 4.5:1. These results are compared with those obtained after theoretical optimization using Minitab software.

\section{Acknowledgements}

The authors sincerely acknowledge NIT Calicut for providing the necessary facilities; UK acknowledges the in- 
stitute for the fellowship.

\section{References}

[1] Vicente, G., Martinez, M. and Aracil, J. (2007) Optimization of Integrated Biodiesel Production Part1. A Study of the Biodiesel Purity and Yield. Bioresource Technology, 98, 1742-1733.

[2] Shibasaki-Kitakawa, N., Honda, H., Kuribayashi, H., Toda, T., Fukumura, T. and Yonemoto, T. (2007) Biodiesel Production Using Anionic Ion-Exchange Resin as Heterogeneous Catalyst. Bioresource Technology, 98, 416-421. http://dx.doi.org/10.1016/j.biortech.2005.12.010

[3] Bouaida, A., Martineza, M. and Aracil, J. (2007) Long Storage Stability of Biodiesel from Vegetable and 414 Used Frying Oils. Fuel, 86, 2596-2602. http://dx.doi.org/10.1016/j.fuel.2007.02.014

[4] Peterson, C.L., Reece, D.L., Hammond, B.L., Thompson, J. and Beck, S.M. (1997) Processing, Characterization, and Performance of Eight Fuels from Lipids. Applied Engineering in Agriculture, 13, 71-79. http://dx.doi.org/10.13031/2013.21578

[5] Demirbas, A. and Kara, H. (2006) New Options for Conversion of Vegetable Oils to Alternative Fuels. Energy Sources, Part A: Recovery, Utilization and Environmental Effects, 28, 619-626. http://dx.doi.org/10.1080/009083190951357

[6] Guan, G., Kusakabe, K. and Yamasaki, S. (2009) Tri-Potassium Phosphate as a Solid Catalyst for Biodiesel Production from Waste Cooking Oil. Fuel Processing Technology, 90, 520-524. http://dx.doi.org/10.1016/j.fuproc.2009.01.008

[7] Vicente, G., Martinez, M. and Aracil, J. (2004) Integrated Biodiesel Production: A Comparison of Different Homogeneous Catalysts Systems. Bioresource Technology, 92, 297-305. http://dx.doi.org/10.1016/j.biortech.2003.08.014

[8] Xie, W., Peng, H. and Chen, L. (2006) Transesterification of Soybean Oil Catalyzed by Potassium 611 Loaded on Alumina as a Solid-Base Catalyst. Applied Catalysis A, 300, 67-74. http://dx.doi.org/10.1016/j.apcata.2005.10.048

[9] Cheng, J., Li, Y., He, S., Shen, W., Liu, Y. and Song, Y. (2008) Reaction Kinetics of Transesterification between Vegetable Oil and Methanol under Supercritical Conditions. Energy Sources, Part A: Recovery, Utilization, and Environmental Effects, 30, 681-688. http://dx.doi.org/10.1080/15567030601082084

[10] Liu, X., et al. (2008) Transesterification of Soybean Oil to Biodiesel Using CaO as a Solid Base Catalyst. Fuel, 87, 216-221. http://dx.doi.org/10.1016/j.fuel.2007.04.013

[11] Kouzu, M., Umemoto, M., Kasuno, T., Tajika, M., Aihara, Y., Sugimoto, Y. and Hidaka, J. (2006) Biodiesel Production from Soybean Oil Using Calcium Oxide as a Heterogeneous Catalyst. Journal of the Japan Institute of Energy, 85, 135-141. http://dx.doi.org/10.3775/jie.85.135

[12] Yan, S., Lu, H. and Liang, B. (2008) Supported CaO Catalysts Used in the Transesterification of Rapeseed Oil for the Purpose of Biodiesel Production. Energy Fuels, 22, 646-665. http://dx.doi.org/10.1021/ef0701050

[13] Yunus, R., Fakhru'l-Razi, A., Ooi, T.L., Iyuke, S.E. and Idris, A. (2003) Development of Optimum Synthesis Method for Transesterification of Palm Oilmethyl Esters and Trimethylolpropane to Environmentally Acceptable Palm OilBased Lubricant. Journal of Oil Palm Research, 15, 35-41.

[14] Kamali, S.K. (2012) Optimization of Sunflower Oil Transesterification Process Using Sodium Methoxide. The Scientific World Journal, 2012, Article ID: 475027.

[15] Gopinath, A., et al. (2010) Effect of Unsaturated Fatty Acid Esters of Biodiesel Fuels on Combustion, Performance and Emission Characteristics of Diesel Engine. International Journal of Energy \& Environment, 1, 411-430.

[16] Agarwal, A.K. (2007) Biofuels (Alcohols and Biodiesel) Applications as Fuels for Internal Combustion Engines. Progress in Energy and Combustion Science, 33, 233-271. http://dx.doi.org/10.1016/j.pecs.2006.08.003

[17] Buyukkaya, E. (2010) Effect of Biodiesel on a DI diesel Engine Performance, Emission and Combustion Characteristics. Fuel, 89, 3099-3105. http://dx.doi.org/10.1016/j.fuel.2010.05.034

[18] Kumar, S.S. and Purushothaman, K. (2012) High FFA Rubber Seed Oil as an Alternative Fuel for Diesel Engine-An Overview. International Journal of Engineering \& Science, 1, 16-24.

[19] Chincholkar, S.P., Srivastava, S., Rehman, A., Dixit, S. and Lanjewar, A. (2005) Biodiesel as an Alternative Fuel for Pollution Control in Diesel Engine. Asian Journal of Experimental Sciences, 19, 13-22.

[20] Tang, Y., et al. (2011) Highly Active CaO for the Transesterification to Biodiesel Production from Rapeseed Oil. Bulletin of the Chemical Society of Ethiopia, 25, 37-42. http://dx.doi.org/10.4314/bcse.v25i1.63359 


\section{Submit or recommend next manuscript to SCIRP and we will provide best service for you:}

Accepting pre-submission inquiries through Email, Facebook, Linkedin, Twitter, etc A wide selection of journals (inclusive of 9 subjects, more than 200 journals)

Providing a 24-hour high-quality service

User-friendly online submission system

Fair and swift peer-review system

Efficient typesetting and proofreading procedure

Display of the result of downloads and visits, as well as the number of cited articles

Maximum dissemination of your research work

Submit your manuscript at: http://papersubmission.scirp.org/ 